\title{
AINDA A SEMIFORMAÇÃO: CONTRIBUIÇÕES DE ADORNO E HORKHEIMER EM TEMPOS DE CIBERCULTURA
}

\author{
AUN LA SEMI-FORMACIÓN: CONTRIBUCIONES DE ADORNO Y HORKHEIMER \\ EN TIEMPOS DE CIBERCULTURA
}

\section{STILL ABOUT SEMI-FORMATION: CONTRIBUITIONS OF ADORNO AND HORKHEIMER IN TIMES OF CYBERCULTURE}

\author{
Adriana, Regina de Jesus SANTOS ${ }^{1}$ \\ Daniella Caroline Rodrigues Ribeiro FERREIRA ${ }^{2}$ \\ Diene Eire de MELLO 3
}

RESUMO: O presente trabalho tem como objetivo norteador desenvolver um estudo crítico e reflexivo acerca da semiformação em tempos de cibercultura. O estudo está amparado na teoria crítica, a partir de uma abordagem teórico-metodológica pautada principalmente nos estudos de Theodor Adorno e Horkheimer, que discute o processo de semiformação na sociedade contemporânea. Compreende-se a educação de maneira ampla, como um espaço tempo necessário para reflexão e tomada de consciência para formar as gerações sobre "ser e estar" no mundo na sociedade da cibercultura.

PALAVRAS-CHAVE: Educação. Semiformação. Teoria Crítica. Cibercultura.

RESUMEN: El trabajo tiene por objetivo orientador desarrollar un estudio crítico y reflexivo sobre la semi-formación en tiempos de cibercultura. El estudio está anclado en la teoría crítica, a partir de un abordaje teórico-metodológico pautado principalmente en los estudios de Theodor Adorno y Horkheimer, que discute el proceso de semi-formación en la sociedad contemporánea. Se comprende la educación de modo amplio, como un espacio-tiempo necesario para reflexión y toma de consciencia para formar las generaciones sobre "ser y estar" en el mundo en la sociedad de la cibercultura.

PALABRAS CLAVE: Educación. Semi-formación. Teoría Crítica. Cibercultura.

ABSTRACT: The present work has as guiding objective to develop a critical and reflexive study about semi-formation in cyberculture times. The study is based on critical theory, from a theoretical-methodological approach based mainly on the studies by Adorno and Horkheimer,

${ }^{1}$ Universidade Estadual de Londrina (UEL), Londrina - PR - Brasil. Docente do programa de pós-graduação em Educação. Doutora em Educação. ORCID: http://orcid.org/0000-0002-9346-5311. Lattes: http://lattes.cnpq.br/3324193224582884. E-mail: adrianatecnologia@yahoo.com.br

2 Universidade Estadual de Londrina (UEL), Londrina - PR - Brasil. Mestranda do programa de pós-graduação em Educação. Pedagogia. ORCID: https://orcid.org/0000-0001-8691-4089. Lattes: http://lattes.cnpq.br/8160445574030980. E-mail: daniellacarolinef@gmail.com

${ }^{3}$ Universidade Estadual de Londrina (UEL), Londrina - PR - Brasil. Docente do programa de pós-graduação em Educação. Doutora em Educação. ORCID: http://orcid.org/0000-0001-6048-8130. Lattes: http://lattes.cnpq.br/9692207152022739. E-mail: diene.eire.mello@gmail.com

RIAEE - Revista Ibero-Americana de Estudos em Educação, Araraquara, v. 14, n. esp. 4, p. 1993-2002, dez., 2019. E-ISSN: $1982-5587$. DOI: https://doi.org/10.21723/riaee.v14iesp.4.12923 
which discusses the process of semi-formation in contemporary society. Education is broadly understood as a necessary time for reflection and awareness to educate generations about "how to be" in the world in cyberculture society.

KEYWORDS: Education. Semi-formation. Critial Theory. Cyberculture.

\section{Introdução}

A sociedade é mediada pelas tecnologias de comunicação e informação, sendo que para alguns autores é denominada de sociedade do conhecimento, sociedade da informação ou cibercultura. Apesar de tais termos serem utilizados para caracterizar um modo de vida em que as tecnologias digitais estão presentes em quase $100 \%$ das atividades desenvolvidas pelo homem, estes utilizam aportes teóricos distintos que não aprofundaremos neste texto. Castels (2005, p. 17), discorda da terminologia "sociedade da informação ou do conhecimento", não porque, para o autor, conhecimento e informação não sejam centrais na nossa sociedade. Mas porque eles sempre o foram, em todas as sociedades historicamente conhecidas.

Assim, lançaremos mão do conceito de cibercultura de Pierre Lévy (1999) para denominar uma nova forma de comunicação gerada pela interconexão de computadores ao redor do mundo, para além da infraestrutura material, que abriga os seres humanos que a mantêm e a utilizam.

Desta forma, o presente ensaio tem como preocupação precípua o ser e estar do sujeito na cibercultura a partir dos pressupostos de Adorno e Horkheimer. Importante ressaltar que tais teorias, apesar terem sido produzidas em contexto histórico, político e social diverso do qual estamos tratando, apresentam-se como imprescindíveis para análise do contexto atual.

Não se trata de uma denúncia a este tempo histórico de maneira pessimista, mas de uma reflexão acerca da necessidade de pensarmos os sujeitos na busca de caminhos para a emancipação, pois a rede de informações na qual estamos enredados é, precipuamente, ambivalente, pois ao mesmo tempo que nos dá liberdade e democratiza a informação também é capaz de gerar formas de conhecer a realidade de maneira, às vezes, equivocada.

Tomando aqui as palavras de Lévy (1999), o fato do cinema e da música serem produtos da indústria cultural não nos impede de apreciá-los, nem de falar deles de uma perspectiva histórica e cultural. Nem a salvação, nem a perdição residem na técnica. Sempre ambivalentes, as técnicas projetam no mundo material as nossas emoções, intenções e projetos. Os 
instrumentos que construímos nos dão poderes, mas somos coletivamente responsáveis, a escolha está em nossas mãos (LÉVY, 1999, p. 16-17).

Assim, só é possível fazermos dos objetos técnicos, das criações e da produção cultural, um caminho, uma escolha, se tivermos a clara compreensão de sua complexidade. Tal compreensão faz-se aqui fundamental para uma possível tomada de consciência e emancipação.

Assim, à luz da teoria crítica, tendo como principais autores Adorno e Horkheimer, buscaremos neste ensaio teórico trazer elementos para reflexões acerca deste tempo histórico, com ênfase na cibercultura. A metodologia utilizada consiste no estudo bibliográfico à luz dos fundamentos da Teoria Crítica, e leituras secundárias que irão elucidar alguns conceitos, tais como: Semiformação, Indústria Cultural, Cibercultura e Educação.

O presente estudo se justifica à medida que não somos apenas consumidores dos produtos técnicos de maneira acéfala, mas homens e mulheres que vivem em uma determinada cultura e necessitamos refletir acerca do que somos, principalmente no campo educacional, para tentarmos uma tomada de consciência sobre estes obstáculos semiformativos.

\section{Ainda a semiformação}

Quando tratamos de Semiformação, recorremos a Adorno, como foco em sua obra Dialética do esclarecimento (1985), em que estão suas primeiras referências à semiformação, ou "semicultura" em seu sentido formativo. $\mathrm{O}$ autor se refere à semiformação como uma forma social imposta por um determinado modo de produção que impacta todas as instâncias e planos de vida.

Adorno e Horkheimer (1985) fazem uma crítica ao homem semiformado, que nas palavras do autor se converte a um sistema "alucinatório", na tentativa de se tornar melhor, na tentativa de dar um sentido ao mundo. Os autores apontam que apesar de toda racionalização, permanecemos irracionais, e mecanismos gerados pela indústria cultural nos modificam, transformando-nos pelas agências do capitalismo, de um modo sutil, que faz parecer o mais sábio a fazer. Assim:

Para o consumidor não há nada mais a classificar que não tenha sido antecipado no esquematismo da produção. [...] todos os detalhes, clichês prontos para serem empregados arbitrariamente aqui e ali e completamente definidos pela finalidade que lhes cabe no esquema. Confirmá-lo, compondoo, eis aí sua razão de ser. O mundo inteiro é forçado a passar pelo filtro da indústria cultural. Quanto maior a perfeição com que suas técnicas duplicam os objetos empíricos, mais fácil se torna hoje obter a ilusão de que o mundo 
exterior é o prolongamento sem ruptura do mundo que se descobre no filme. (ADORNO; HORKHEIMER, 1985, p. 117-118)

Dessa maneira, o mundo, que permanece irracional, seria reconstruído em um molde planejado que substitui o que seria a experiência do consumidor, antecipando os impactos do capitalismo, resultando na ilusão de que o mundo seria o prolongamento da produção nos termos da indústria cultural.

Nesse viés, Adorno, em seus estudos, deixa-nos a compreensão de que todos os indivíduos que estão inseridos em uma sociedade capitalista são, necessariamente, vítimas de uma falsa democratização da cultura, na qual tentam melhorar as condições existentes, que por inúmeras vezes está sob a égide da lógica do consumo e da indústria cultural.

Sobre esse assunto, Freitag (1988) acrescenta que os principais traços da indústria cultural são referentes à produção artística e cultural dos indivíduos, organizada sempre de uma maneira capitalista, com o intuito de uma introdução no mercado, por sua propagação e consumo. Desta maneira, se esta sociedade é marcada pelo consumo e produção capitalista, certamente suas ideias e trabalhos sobre obra de arte, cultura, ideias, valores, transformam-se também em mercadoria.

Convém ressaltar que a indústria cultural consiste na reprodutividade da arte, da cultura e do conhecimento em formato de padronização, uniformização e adaptação social. Neste contexto, os bens culturais passam a existir em função de que as pessoas se apropriem destes apenas como forma de lazer, prazer e espetáculo, visando apenas o lucro do capital, fazendo com que os mesmos se tornem dependentes de sua lógica, distanciando-se do que deveria, em última instância, ser o processo de conhecimento, desenvolvimento e formação humana.

Ou seja, o processo de reprodução é o eixo norteador, pois a indústria cultural é considerada integração voluntária, pelo alto, de seus consumidores, e fator que "duplica na consciência dos homens o que existe", formando a consciência ao confirmar o mundo na ordem estabelecida (ADORNO, HORKHEIMER, 1985, p. 175).

A mídia em geral constitui um contexto privilegiado para apreender esse esquema semiformador. Seja de modo direto, como no filme, em que por uma "coincidência" revela-se a $\log o^{2}$, seja também pela sutil expressão de um personagem; nesse esquema, percebe-se o quanto a mídia tenta a todo o momento semiformar os indivíduos.

Destarte, podemos mencionar o quanto os meios de comunicação utilizam de diversos mecanismos para transformar em entretenimento as obras de pensamento.

${ }^{2}$ Este termo é próprio da área de marketing e propaganda e corresponde a logotipo.

RIAEE - Revista Ibero-Americana de Estudos em Educação, Araraquara, v. 14, n. esp. 4, p. 1993-2002, dez., 2019. E-ISSN: $1982-5587$. 
Visto que a destruição dos fatos, acontecimento e obras segue a lógica do consumo, da futilidade, da banalização e do simulacro, não espanta que tudo se reduza, ao fim e ao cabo, a uma questão pessoal de preferência, gosto, predileção, aversão, sentimentos. É isto o mercado cultural (CHAUÍ, 2006, p. 22).

Esta é a consequência da lógica dominadora a respeito dos simulacros e do gosto que espanta, mas também atrai todos os indivíduos de múltiplas idades, de classes sociais distintas, com uma certa alienação quase doentia com seus gadgets imersos em uma gama variada de redes sociais, que nos torna consumidores e dominados pelo "mar de informações". Assim, a interferência da indústria cultural, da mesma maneira nos submete à liberdade e à atividade do sujeito pensante, modificando sua capacidade de perceber e sentir, gerando nele o conformismo, a adaptação, a regressão de seus sentidos.

De maneira quase ingênua, consumimos produtos como forma de lazer que tomam nosso mundo, nosso tempo, nossas relações e nossas vidas. O diálogo, pessoalmente estabelecido, tem sido substituído pela comunicação efetuada através de telas de múltiplos artefatos que nos rodeiam e fazem parte do nosso cotidiano. Ao longo do dia, alternamos as telas, da TV para os Smartphones, para os computadores de trabalho. A facilidade de acessar informações e nos comunicarmos com um grande grupo de pessoas em tempo real traz a sensação de liberdade e certo encantamento ao selecionarmos os conteúdos que queremos ler, ver, acessar e retransmitir.

A sensação de liberdade é falsa, pois as informações que nos são ofertadas por meio dos múltiplos canais já foram previamente selecionadas por sistemas e algoritmos. Ou, seja, à medida que vamos consumindo uma determinada informação, vamos deixando rastros na rede que são utilizados pelos grandes conglomerados financeiros para fins comerciais ou políticos. Mais e mais informações, com o mesmo viés ou caráter ideológico, nos são ofertadas, ou seja, o simples ato de navegar na internet, ler despretensiosamente as informações nas redes sociais, ou comprar qualquer produto, gera uma série de dados.

Colbo (2019) afirma que é necessário entender que as várias formas de manipulação e poder são aparentemente invisíveis nos espaços digitais. A Internet é uma fábrica de dados e nós agimos como consumidores doutrinados sem nos atermos às regras de constituição da rede, agimos ainda como intermediários digitais influentes.

Diante disso, o conceito de semiformação se mostra presente ao padronizar informações, em alguns casos, recheadas de Fake News, dando a impressão de que cada indivíduo agora é sujeito pensante e consciente por ter uma variada gama de informações que podem ser replicadas, transformadas e discutidas por outros indivíduos. 
Assim, o sujeito semiformado toma-se como sujeito do mundo que meramente reproduz. "Para ele a construção parece "natural" a dominação consequente da natureza se impõe de uma maneira cada vez mais decidida e passa a integrar toda a interioridade humana" (ADORNO; HORKHEIMER, 1985, p. 208).

Nessa mesma perspectiva, Adorno, em Crítica cultural e sociedade (1949), dá apontamentos acerca da ideologia, que em sua opinião seria a própria sociedade. De modo igual, os homens permanecem sujeitos de uma reprodução da vida.

Que a semiformação, apesar do esclarecimento da ilustração e da difusão de informações e mesmo por seu intermédio se tornou a forma dominante da consciência contemporânea - é justamente isto que exige uma teoria mais ampla. A ideia de cultura não deve ser sacrossanta para ela, conforme é hábito da própria semiformação (ADORNO, 1979, p. 94).

Semiformação é "o espírito tomado pelo caráter fetichista da mercadoria” (ADORNO, 1979, p. 108). Iop (2009) define como uma formação do indivíduo por meio da industrialização da cultura, em que os produtos perdem sua essência cultural, pois são transformados pelo processo industrial em semicultura, assim, os seus produtos servirão de conteúdo formativo para a sociedade; uma vez que está em várias instâncias representativas da vida social e, até mesmo, em espaços e contextos de indivíduos que se consideram "emancipados e críticos" pelo simples fato de terem acesso à informação. Em tempos de cibercultura, a informação manipulada pode gerar efeitos catastróficos na forma de pensar dos sujeitos.

A quantidade de informações manipuladas em diversos formatos que recebemos ou acessamos cotidianamente como um fast food de pensamento, oferece pouco espaço para análise e crítica. A forma como são produzidas, com imagens, sons, memes, recorte e bricolagem com vídeos como algo pronto, acaba por passar uma ideia de verdade absoluta. Para Adorno não basta examinar a semiformação sem ter como referência o contexto de produção da sociedade, como formação social autogerada pelos homens e aprendida em sua dialética histórica. Neste sentido, torna-se imprescindível a compreensão da forma de produção da informação e seu caráter ideológico.

A resistência por meio do conhecimento consiste em pensar o papel da educação em favor do desenvolvimento da experiência do pensar crítico e emancipado dos sujeitos. 


\section{Educação como forma de resistência: uma possível saída}

A partir da problemática anunciada acima, entendemos que é possível e necessário espaços/tempos formativos e emancipatórios. A educação é, sem dúvida, uma forma de resistência para o pensar e agir dos sujeitos.

Nesse viés, a educação para ser efetiva, necessário se faz refletir sobre a crítica da semiformação, e entender o seu processo, para então, pensar em uma possível emancipação, que para Adorno seria o elemento central da educação. "A orientação normativa da educação não é imposta de fora, mas deve saltar de sua configuração histórica que, por suas contradições, exige objetivamente a partir de si própria sua transformação" (ADORNO, 1999, p. 183).

Assim, é preciso criar formas de organização nas instituições educativas que possam contribuir para que o indivíduo possa desenvolver estratégias cognitivas capazes de compreender e analisar o contexto da sociedade para a contradição e para a resistência, a fim de desmistificar a ideia de um consumo de informações e ideias que necessitam de reflexões e análises mais profundas. É, então, de forma indissociável que uma das principais tarefas da escola é desenvolver nos alunos a capacidade de reflexão crítica e de tomada de decisões, e também ir além das formas de reprodução e alienação dos conhecimentos preestabelecidos da semiformação.

Ressalta-se que Adorno, mesmo não sendo um teórico da educação, nos ampara com seu arcabouço substancial de análise para pensarmos os processos educativos de forma ampla, com vistas à resistência frente ao que está posto pelos moldes sociais e econômicos. Na história concreta dos sujeitos, mais do que nunca cabe à escola desvelar e difundir programaticamente as resistências expressas de distintas formas, que no momento oferecem alternativas ao estabelecimento decorrente da indústria cultural.

Entretanto, os professores devem estar capacitados para lançar mão, inclusive, dos próprios recursos da indústria cultural para possibilitar que as novas gerações venham a recriar as relações com o cenário da cibercultura.

A indústria cultural faz parte de um complexo aparato que envolve a realidade do educando, e como tal representa os desafios para a transformação do ser humano. É imprescindível, portanto, que o processo educativo tenha presente a formação da consciência dos professores, fortalecendo os valores da ética e da dignidade humana.

Todavia, falar de consciência crítica tornou-se lugar comum em diversos estudos nas mais variadas áreas, mas o processo que envolve a reflexão crítica é muito mais complexo e 
necessita de rigorosidade, envolvimento, e, em hipótese nenhuma, deve ser visto como um caminho sem fins e objetivos, visto que:

[...] A reflexão crítica não se pode ser concebida como um processo de pensamento sem orientação. Pelo contrário, ela tem um propósito muito claro, ao definir-se diante dos problemas e atuar consequentemente, considerandoos como situações que estão além de nossas próprias intenções e atuações pessoais, para incluir sua análise como problemas que têm sua origem social e histórica (CONTRERAS, 2002, p. 163).

Como exposto pelo referido autor, a reflexão crítica é um processo de tomada de consciência do docente, que está além de suas intenções, pois a criticidade que permeia esta reflexão permite-lhe questionar a estrutura social que acaba por envolver seu trabalho, possibilitando-o uma noção crítica e consciente da prática por ele desenvolvida e das consequências dessa prática social na sua atividade docente.

Acreditamos, ainda, que a teoria crítica pode ser um dos caminhos para o desenvolvimento da consciência no processo educativo, desempenhando um papel fundamental para que ele se desenvolva de uma melhor forma.

Neste caso, é possível combater a falsa consciência como algo do próprio veneno imposto em nosso cotidiano. Como afirma o autor Adorno (1995), será por meio da educação que podemos encontrar a possibilidade de resistência para não cairmos na semiformação, será pela tomada de consciência e de autorreflexão que o indivíduo poderá ir além desta lógica.

Portanto, as redes, na sociedade informatizada, não são por si só o problema, mas a forma como nos apropriamos das mesmas. Tomamos aqui as palavras de Castels (2005, p. 19):

\footnotetext{
Assim, a questão não é como chegar à sociedade em rede, um autoproclamado estádio superior do desenvolvimento humano. A questão é reconhecer os contornos do nosso novo terreno histórico, ou seja, o mundo em que vivemos. Só então será possível identificar os meios através dos quais, sociedades específicas em contextos específicos, podem atingir os seus objetivos e realizar os seus valores, fazendo uso das novas oportunidades geradas pela mais extraordinária revolução tecnológica da humanidade, que é capaz de transformar as nossas capacidades de comunicação, que permite a alteração dos nossos códigos de vida, que nos fornece as ferramentas para realmente controlarmos as nossas próprias condições, com todo o seu potencial destrutivo e todas as implicações da sua capacidade criativa.
}

Assim sendo, é por meio de reflexões e apropriações da teoria crítica que podemos oferecer possibilidades de pensar pelo caminho da autocrítica, a possibilidade da educação, desenvolver o exercício de uma atividade intelectual, que venha a oferecer uma formação pautada na emancipação e criticidade do ser humano. 


\section{Considerações finais}

O objetivo deste texto foi desenvolver um estudo crítico e reflexivo acerca da semiformação em tempos de cibercultura, tomando a educação como uma possível forma de emancipar os indivíduos para ser e estar na sociedade de uma forma em que os mesmos tenham autonomia.

Ressalta-se que não nos cabem visões tecnofóbicas acerca da sociedade em que vivemos, mas perceber que a sociedade mediada pelas tecnologias, aqui denominadas de cibercultura, é por si só ambivalente, pois as redes trazem consigo uma série de possibilidades e fluxos que são imprescindíveis para pensar a democratização da informação. Entretanto, trazem também traços de uma semiformação ao propiciar aos indivíduos a falsa ideia de liberdade.

Deste modo, entendemos que é papel da educação discutir e promover uma formação que seja capaz de propiciar aos indivíduos ferramentas de compreensão e análise, tais como os artefatos culturais, sociais e tecnológicos, e estes necessitam ser compreendidos como uma linguagem de mediação no processo de ensino e aprendizagem, tendo como foco o sujeito como um ser de intencionalidades que constrói e reconstrói a sociedade onde está inserido, superando dessa maneira a perspectiva que o ser homem fique refém de tais artefatos.

Portanto, entendemos que a educação por meio da teoria crítica poderá apontar caminhos, embora não muito simplistas, como o de apresentar que existe uma consciência livre e crítica que poderá ser direcionada para uma possível transformação, onde a mesma poderá romper com a semiformação em tempos de cibercultura.

\section{REFERÊNCIAS}

ADORNO, T. A indústria cultural. In: COHN, Gabriel (Org.). Comunicação e indústria cultural. 4. ed. São Paulo: Nacional, 1979.

ADORNO, T. Teoria da semicultura. Educação e sociedade, Campinas: CEDES, n. 56, p. 388-411, dez. 1999.

ADORNO, T. Dialética do esclarecimento. Trad.: Guido Antonio de Almeida. Rio de Janeiro: Jorge Zahar, 1985.

ADORNO, T. Indústria Cultural e sociedade. Tradução de Juba Elisabeth Levy ( et al.). São Paulo: Paz e Terra, 2002.

ADORNO, T.; HORKHEIMER, M. Educação e Emancipação. Trad.: Wolfgang L. Maar. Rio de Janeiro: Paz e Terra, 1995. 
BUENO, S. F. Semicultura e educação: uma análise crítica da revista Nova Escola. Revista Brasileira de educação, v. 12, n. 35, maio/ago. 2007.

CASTELS, M. A sociedade em rede: do Conhecimento à Acção Política. Imprensa Nacional, Casa da Moeda, Lisboa, Portugal, 2005.

COLBO, C. Acepto las Condiciones: Usos y abusos de las tecnologías digitales, Fundación Santillana, Madrid, 2019.

CONTRERAS, J. Autonomia dos professores. São Paulo: Cortez, 2002.

FREITAG, B. A Teoria Crítica ontem e hoje. São Paulo: brasiliense, 1988.

LÉVY, P. Cibercultura. São Paulo: Editora 34, 1999.

IOP, E. Formação cultural, semicultura e indústria cultural: contribuições de Adorno sobre a emancipação. Revista Espaço Pedagógico. Passo Fundo, v. 16, n. 2, p. 20-33, jul./dez.2009.

\section{Como referenciar este artigo}

SANTOS, Adriana Regina de Jesus; FERREIRA, Daniella Caroline Rodrigues Ribeiro; MELLO, Diene Eire de. Ainda a semiformação: contribuições de Adorno e Horkheimer em tempos de cibercultura. Revista Ibero-Americana de Estudos em Educação, Araraquara, v. 14, n. esp. 4, p. 1993-2002, dez., 2019. E-ISSN: 1982-5587. DOI: https://doi.org/10.21723/riaee.v14iesp.4.12923

Data de submissão: $25 / 06 / 2019$

Data de aceite: $26 / 07 / 2019$

Data de publicação: 01/09/2019 